Fecha de recepción: mayo 2021 Fecha de aceptación: junio 2021 Versión final: julio 2021

\section{La hiperinfografía, diálogo en el ámbito del diseño}

Adriana Vigueras Villaseñor ${ }^{(1)}$

Resumen: El diseño es una disciplina que se apoya en imágenes y textos; con una composición, color y elementos formales que conforman el propio diseño. El diseño está presente desde en las editoriales hasta en el uso de los medios tecnológicos; desde objetos de diseño bidimensionales a tridimensionales. En efecto, el producto de diseño está dirigido al público con diferentes edades, géneros, clases sociales y alcances educativos. Por medio de este área del diseño, se ponen en relieve los elementos culturales que han permanecido en la historia, se enseña, difunde o promocionan objetos, ideas y hasta personas. Cualquier individuo, a lo largo de su existencia, ha diseñado alguna vez en su vida; ha tratado de que algo pueda visualizarse de forma agradable, contrastante, brillante o cualquier otra cualidad que compete a esta disciplina. Más aún, existen diferentes productos del diseño dirigidos al usuario: folletos, carteles o infografías; conformados por imagen y texto, entre otros.

En este artículo se desarrollará el diálogo acerca del significado de la infografía y de los grandes formatos, denominados "hiperinfografías". Estas últimas son un producto de diseño que sobrepasa los estándares de tamaño. Puntualmente, la infografía periodística tiene su antecedente como megainfografía. Estos son, formatos impresos infográficos en periódicos tamaño sábana, aproximadamente de 16 pliegos. En el caso de la hiperinfografía se la denominó así por ser más grande que un mega y exceder las dimensiones antes mencionadas.

Palabras clave: Diálogo - infografía - hiperinfografía - dimensiones - tamaño - legibilidad - leibilidad.

[Resúmenes en inglés y portugués en la página 146]

(1) Licenciada en Diseño Gráfico por la Facultad de Estudios Superiores Acatlán, UNAM. Magister en Artes Visuales en la Academia de San Carlos, UNAM. Doctorado en Arte y Diseño en la Academia de San Carlos, UNAM. Profesora en la Facultad de Estudios Superiores Acatlán, UNAM; Universidad Justo Sierra; Universidad Tecnológica de México y Universidad Iberoamericana. 


\section{Introducción}

Primeramente, es importante esclarecer el significado de "infografía", algunos autores mencionan - de manera generalizada - que deviene de los vocablos info y grafía. Inicialmente info estaba ligada a informática, esta palabra determina todo lo concerniente a la tecnología computacional, ante esto José Luis Valero (2009. p. 123) menciona precisamente que "ni el vocablo info viene de informática ni grafía viene del concepto de animación que hoy se le pretende dar. Tampoco infografía es lo mismo que información gráfica, puesto que hay otras formas en el periodismo que también lo son." El vocablo informática proviene del boom en los ochentas con la Macintosh Apple (1984) que facilitaba el uso de gráficos. Por ejemplo, en México a finales de dicha década y principios de los noventas, la computadora personal estaba en su auge; en 1992, un ordenador apenas contaba con capacidad para unos megabytes y una impresora láser tenía resolución de 120 dpi's. Analizado desde la actualidad, resulta irrisoria la calidad de esto, Más aún, con el fin de que la calidad no mermara, un original mecánico, necesitaba ser fotografiado y obtener un negativo, luego se imprimía en láser tamaño carta aumentando el diseño al doble, (200\%). Hoy en día la salida de impresión alcanza los 2400 dpi's. En este orden de ideas, se le atribuía el término info a informática y no a información, debido a los cambios catalizados y posibilitados por la introducción de nuevos medios tecnológicos. Lo mismo sucede con grafía, así que infografía no sólo es informática gráfica ni información gráfica, va más allá de estos conceptos. La grafía está relacionada con lo gráfico, todo aquello que puede ser representado por medio de imágenes gráficas, desde una simple ilustración o fotografía hasta conceptos más elaborados como un esquema o un dato estadístico diseñado a priori para una infografía. Santos Zunzunegui menciona que la imagen es:

Soporte de la comunicación visual que materializa un fragmento del entorno óptico (universo perceptivo) susceptible de subsistir a través de la duración y que constituye uno de los componentes principales de los medios masivos de comunicación (fotografía, pintura, ilustraciones, esculturas, cine, televisión) (1995, p. 24).

Con esto puede mencionarse cómo Santos Zunzunegui en Pensar la imagen habla de hacer visible nuestro derredor por medio de gráficos que se requieren para hacer explícita la información, donde la grafía apoya al texto y viceversa. En síntesis, la imagen es parte primordial de la infografía para visualizar objetos o personas. 


\section{Desarrollo}

La infografía se presenta por primera vez como tal en el marco del ejercicio periodístico, disciplina precursora que utilizó el diseño de imágenes concretas y sintetizadas usadas por computadora. De allí, y tal como se anticipó anteriormente, hace referencia al vocablo informática, por el empleo del ordenador, y luego el sentido info refiere a "información". José Luis Valero menciona que la información gráfica es parte de la infografía, por el uso de la información y la grafía. Sin embargo, ésta tiene un proceso más riguroso, metodológico y concreto para dar el mensaje de manera adecuada, dirigido al usuario indicado y con características de diseño e información que hace que una infografía sea llamada así. El inicio de la impresión periodística, es un producto de diseño para un público que goza de la lectura. Esto se puede ver en la cantidad de columnas y texto que los conformaban, dejando el papel gráfico para fotografías, comics dominicales, o cartones políticos que hacen su aparición como una síntesis visual de los acontecimientos a su derredor, integrando el texto a la imagen, creando nuevos públicos y transformando lo textual en visualidad. Por ello, el auge de la infografía resume el texto en apoyo gráfico, Hans Hoffman pintor alemán expresionista dijo: "Simplificar significa eliminar lo innecesario para que lo necesario pueda hablar" (en Tricio, 2015, p. 21), y esta aseveración es una buena definición, aplicable a la información tanto textual como visual en el uso de una infografía.

Precisa Valero (2001) que la infografía periodística es una "aportación informativa, realizada con elementos icónicos y tipográficos, que permite o facilita la comprensión de los acontecimientos, acciones o cosas de actualidad o algunos de sus aspectos más significativos, y acompaña o sustituye al texto informativo" (p. 21). Esta descripción de Valero coincide con lo sostenido por Hoffman, no obstante, es curioso que hablan de la infografía, más no es definida, dado que para su definición es menester considerar el diálogo entre el diseñador y comunicadores. En efecto, quienes hablan de la infografía son comunicadores: Valero, Cairo, De Pablos, Leturia, y entonces ¿dónde están los diseñadores hablando de infografía? No los hay, por ello se abre el debate para iniciar este camino de debate con respecto al tema.

En relación a la transformación de la infografía a través del tiempo, menciona De Pablos (1998) que siempre ha existido este producto de diseño, pues enfatiza el uso de un binomio bI+T, en donde b es binomio, I de imagen y $\mathrm{T}$ de texto. No se concuerda del todo con esta aseveración, dado que va más allá de referirse solo a la imagen y al texto, sino que comprende este binomio como base generalizada. Entonces, se puede pensar en una viñeta o historieta que conjuga estos dos elementos, más no es una infografía. Por ejemplo, los datos informativos que presentaba Da Vinci en sus cuadernos también utilizaban este método de imagen y texto, sin embargo, no son infografías, ya que sólo colocaba una imagen y texto de apoyo donde narraba lo visible en la imagen. Lo antedicho, en síntesis se puede ver como parte de los antecedentes de la infografía. Aunque el binomio de De Pablos no conforma una definición precisa para el término antes mencionado, estos dos elementos son la base en el diseño de este concepto, sumado a las características textuales y gráficas que permiten que esta dupla sea denominada "infografía" y con ello si se concuerda, es la base de un infograma del que se hablará más adelante. 
Sullivan menciona características que debe contener un infografista, el creador de las infografías, o como él lo menciona el infógrafo.

Los infógrafos deben ser, ante todo, comunicadores que saben anticipar una infografía con la rapidez de producción que la prensa necesita, pero que tengan otras cualidades añadidas como la "creatividad" de un artista, la capacidad de distinción de un diseñador y la habilidad, y rapidez mental de un periodista o, más importante, la habilidad para pensar como periodista (1992, p. 164).

Significa que se le agregaría al binomio creatividad, capacidad sintetizadora del diseñador y habilidad-rapidez mental del periodista. Esta perspectiva considera como hacedor de infografías sólo al periodista porque se sugiere pensar como un reportero.

Más aún, algunos autores mencionarán a la infografía a manera de "infos", síntesis de la palabra.

El trabajo de los periodistas ha sido fundamental para el diseño de este concepto, ya que fueron los precursores de su uso, siendo su antecesor el snap shots (término de diseño sin traducción al español), publicados en el USA Today en 1982. Los snap shots han sido diseñados como elementos primordiales de la información a manera de gráfico, tenían un mismo tamaño que era de $10 \mathrm{~cm}$ de altura y ocupaba las dos columnas. Estaba colocado en la misma sección del periódico y se apoyaba normalmente de una noticia del semanario.

El snap shots trae como consecuencia el uso de información dependiente del texto. Aunque, puede haber infografías independientes, que no secunden una información dentro del periódico y las dependientes, que apoyen al texto presentado en sus costados. Según el tipo, pueden caracterizarse como infografía periodística independiente o infografía periodística dependiente (Vigueras, 2018). El otro elemento novedoso y llamativo de este producto de diseño es la impresión en color en el contenido del diario. En México, el color se imprimía en las historietas de suplementos dominicales. En el interior del diario, el color se pudo visualizar recién en los noventa, inicialmente compartiendo el color que era pagado por parte del anunciante. Se trabajaba en la compaginación para aprovechar la tinta y posteriormente se usaba el color en todo el ejemplar, como sucedía en el periódico Reforma, pionero en esta aplicación colorímetra.

El esquema que primaba en el diseño de las noticias, respondía a la teoría estadounidense denominada las 5 W's y 1 H. Esta regla fue mencionada por Lorenzo Vilches (1987, p. 81): 1) ¿Qué? (what), suceso global o total; 2) ¿Quién? (who), autor, actor principal; 3 ) ¿Cuándo? (when), el tiempo; 4) ¿Dónde? (where), lugar; 5) ¿Por qué? (why), causas y efectos; 6) ¿Cómo? (how), funciona, sucede, realiza.

Éstos principios, se han retomado para el diseño de una infografía, y se deben responder, tanto desde la parte informativa como gráfica (Leturia, 1998). Con ello se observa que se van agregando características que secundan al diseño de una infografía, la cual no sólo se compone del bI+T, sino que deberá cumplir y cubrir aún otras características. Entre ellas se tiene la legibilidad y leibilidad (el primero es para que se puedan distinguir los rasgos de la letra, sus formas y contra formas; mientras la segunda es para que se entiendan el contenido y significado de las palabras), términos que tienen relación con la distinción de 
rasgos de la letra para que puedan ser reconocidas y el contenido del mismo pueda tener un significado informativo al usuario respectivamente.

El texto es un elemento base de la infografía, a fin de cumplir con el requisito de legibilidad, debe ser claro y comprensible desde la parte visual pero también desde el contenido. Con respecto a este último punto el texto debe ser sencillo, claro, preciso, sintetizado, de fácil lectura para el usuario.

La legibilidad se circunscribe al título, subtitulares y texto o cuerpo que se presente acompañando los esquemas o fotografías necesarios para explicar procesos. Es inexcusable cuidar la ortotipografía, y procurar que la tipografía sea colocada de la manera correcta, así como el puntaje, la familia y la estructura de la misma en el diseño.

Las imágenes que se emplean en las infografías como esquemas, fotografías, ilustraciones, datos cuantitativos, mapas relacionales, croquis o planos, organigramas, procesos, líneas de tiempo proporcionan una explicación concreta y sintetizada del tema, con texto informativo-gráfico al perceptor, se muestran en un mismo plano de tiempo: secuencias, imágenes, esquemas (sinergia y atemporalidad). A esta combinación de imagen y texto de manera gráfica compositiva se la denomina "infograma”, que es la parte básica del concepto mencionado con anterioridad. A su vez, varios infogramas conformarán una infografía. José Luis Valero las define como:

La combinación de textos e imágenes cercados mediante un recuadro, pero sin la autonomía que tienen las infografías y por ello se sitúan a medio camino entre ellas y las unidades gráficas elementales (Valero, 2001, p.109).

Los infogramas toman sentido y significado a partir de su unión en la infografía. Cada uno por separado no denota ninguna acepción especial, además como parte de su interpretación gravitará el color para dar significaciones (tal como es estudiado por la psicología del color). El color puede ser usado en el fondeado, el texto y la imagen de tal manera que el infograma sea llamativo. También se utiliza el color para ordenar el espacio, la información y simultáneamente la lectura en el plano; otra de las estrategias para esta ello consisten en trabajar con las jerarquías, la unidad o variedad dentro de la composición, entre otras.

La infografía, en general se diseña a partir de un foco gráfico, mencionado en una entrevista con Ernesto Alcántara (2014), que es el punto de atención o atracción de la composición y que a partir de ahí se tiene la lectura global de los componentes que se encuentren a su alrededor o jerárquicamente organizada.

Con esto se puede ultimar, a pesar de no contar con un significado concreto, que "la infografía es infografía", locución proporcionada por Valero y a lo que concluyeron varios infografistas en 2014. Se puede definir, desde la perspectiva del autor de este comunicado, que la infografía es una combinación de texto e imágenes conformadas en un espacio determinado, dinámicas (digitales) o estáticas (impresas) en el cual se utiliza un titular, texto en el cuerpo gráfico, imágenes como esquemas, fotografías, ilustraciones, datos cuantitativos, mapas relacionales, croquis o planos, organigramas, procesos, líneas de tiempo para dar explicación concreta al tema, con una información textual y gráfica al perceptor. 
Puede ser dependiente o independiente a un texto de acompañamiento, utilizando el color y composición para llamar la atención por medio de un foco gráfico y dar lectura de manera ordenada, coherente, legible y leíble, así como la sinergia en su composición gráfica. Por el momento, se ha definido a la infografía con base en los elementos compositivos o textuales, sin embargo, se examinarán clasificaciones para poder llegar a la palabra hiperinfografía (término propuesto por la autora en 2014), gracias al apoyo del doctor Jaime Reséndiz, docente de la Facultad de Artes y Diseño de la UNAM.

Las infografías han sido clasificadas por un número variado de autores que se han tratado de ordenas el prolífico universo de las infografías según ciertos puntos específicos. Por ejemplo, Raymond Colle (2004) las divide de acuerdo con su tema en: la infografía pedagógica, infografía científica, infografía publicitaria, infografía periodística, informes empresariales y modo de empleo (instrucciones de uso).

María Mercedes Martínez (2008) se enfoca en la composición, y las divide según estén diseñadas con gráficos de manera radial, gráficos separados, gráficos integrados o gráficos en serie.

Raymond Colle (2004) y Rodrigues (2009) las dividen en infografías de $1^{\text {er }}$ nivel (1-2 infogramas), $2^{\circ}$ nivel (3-5) y $3^{\text {er }}$ nivel (6 o más). La diferencia radica en que Colle incorpora las infografías de los medios impresos dentro de esta clasificación y Rodrigues se enfoca en las digitales.

Más recientemente, Cordeiro (2018. p. 19) propone la interacción como elemento de análisis, y esto abarca a "los modelos de realidad virtual periodística, inmersiva, tridimensional, con el objetivo de categorización y construcción conceptual”. En el ámbito periodístico a este tipo de infografías los han denominado "hiperinfografía". De acuerdo con este autor, se agregaría entonces la infografía de $4^{\circ}$ nivel, utilizando el prefijo hiper por hiper media, y por la sofisticación del diseño que representa.

La hiperinfografía, desde el enfoque de diseño, hace hincapié en el formato y en la densidad requerida de trabajo investigativo para el diseño. La palabra formato viene del francés format; del latín formare, y a su vez de forma, donde se precisa, formato es la forma, o como dice el Pequeño Diccionario de Diseño, "sentido del tamaño dado al área de un diseño" (p. 49) y agregando también el soporte donde se diseña. Por su parte, la palabra soporte tiene raíz latina del sufijo "sub" que se refiere a algo que se encuentra por debajo, como subterráneo, sublingual, subtítulo y "portare" que significa llevar, portar, de ahí que su significado es el sustentáculo de algo, lo que se encuentra debajo del diseño.

Claro está que el soporte tendrá una dimensión o tamaño, la palabra dimensión viene de la raíz latina dèmètiri que significa medir, el tamaño o envergadura de una persona, objeto o cualquier ser animado e inanimado.

Así que revisando formato, soporte y dimensión (terminología coloquial entre el lenguaje del diseñador), se puede apuntar, a considerar el criterio de clasificación de la infografía de acuerdo con su magnitud. También cabe considerar la propuesta de incorporar como parte del criterio, que es lo que se sostiene en este artículo, el diálogo interpretativo. En este sentido, variará la hiperinfografía en relación con el tema, composición y cómo se presente a la audiencia, ya sea en medios impresos — como se mencionaba primordial- 
mente (periódicos, revistas, folletería)—; o digitales — a manera de páginas WEB—, o el mensaje inclusivo (realidad virtual y realidad aumentada) (Cordeiro, 2018).

Para poder designar el término hiperinfografía, cabe mencionar a tres autores que constituyen parte de los antecedentes del surgimiento del término Eduardo Pérez (1999), utiliza el término megainfográfico cuando se tiene una infografía periodística de gran tamaño en dos sentidos: cuando el tiempo de construcción e investigación para el diseño de la misma (que pueden ser semanas o meses de su elaboración) es extenso; y también cuando el tamaño sobrepasa la magnitud original de un periódico, es decir que excede esta proporción ya sea por medio del tabloide, berlinés o por mostrar un formato sábana en doble hoja, o hasta 16 pliegos de dicho semanario. Por ejemplo, Ernesto Alcántara (infografista del periódico Excelsior), en una exposición presentó un megainfográfico de 16 páginas sábana, patrocinada por el Banco Banorte. Participaron en su diseño seis personas e implicó dos meses en investigación y diseño. El tema fue para conmemorar los 200 años de la Independencia y 100 de la Revolución mexicana.

El segundo autor, Valero, que constituye otro antecedente del concepto hiperinfografía, en una entrevista vía correo electrónico (2014) menciona que él llamó "mural infográfico" a un diseño para un partido político de 4x1.6 metros; es decir que tamaño grande, mas no se especificaron características del mismo.

Por último, Raymond Colle (2004) también cita al megagráfico, donde explica el autor que cubre dos páginas en una revista y una gran cantidad de información; que pudiese ser intrincada su lectura por la cantidad de datos presenciados en el diseño.

Cuadros infográficos más complejos, con abundante información, que no respetan las reglas de simplificación y economía de espacio: al contrario, se adueñan de la totalidad de una página (o una doble página, en el caso de las revistas) para acumular la mayor cantidad posible de información (Colle, 2004, p. 4)

Con esto, puede apreciarse que los megainfográficos, los murales infográficos y los megagráficos tienen un punto en común: el tamaño, del latín tam magnus (tan grande). Así que el punto en común está dado por el tamaño "tan grande, que las diferenciará, de otras categorías. En consecuencia, las hiperinfografías están caracterizadas por tener las mayores dimensiones (Vigueras, 2018). La autora, denomina de esta manera, desde el punto de vista del diseñador gráfico, la parte compositiva, extensión y diseño, a diferencia del comunicador o periodista que se enfoca en el contenido (Vigueras, 2018).

¿Por qué denominarlo hiperinfografía? Esta denominación responde a la monumentalidad o tamaño del formato. La palabra gran formato es un término utilizado en las artes gráficas, equiparado con las gigantografías, las cuales son impresiones en formatos monumentales, pero sólo refiere a la impresión, independientemente del diseño que se utilice. Aunque pueden emplearse materiales o soportes variados para ello, como lona o vinil impreso, no obstante, si se utilizara este término de gran formato o gigantografías para las infografías grandes, se tendría un problema de confusión, por ello el cambio de nomenclatura o término. 
Colle, (2004, p. 4), menciona en su artículo y enfatiza que se requiere "Una unidad espacial en la cual se utiliza una combinación (mezcla) de códigos icónicos y verbales para entregar una información amplia y precisa, para la cual un discurso verbal resultaría más complejo y requeriría más espacio". Así que el espacio se necesita cuando hay más información, y a mayores datos es más formato. En consecuencia, una hiperinfografía, por su magnitud, abarcará más información y soporte gráfico, y por ende puede ser colocada en vallas, muros, MUPIS (mobiliario urbano publicitario), o sitios especialmente diseñados para este fin.

Por lo anterior, y dado su tamaño, se debe considerar la altura y distancia de colocación para su legibilidad y leibilidad adecuada al usuario, además de ser esta hiperinfografía atractiva para contar con tiempo suficiente, y así detenerse a leerla por la cantidad de información gráfica y visual al exponer un tema específico.

Una hiperinfografía, por su tamaño monumental, puede ser diseñada a partir del $2^{\circ} \mathrm{y}$ $3^{\text {er }}$ nivel de acuerdo con los autores Raymond Colle y Adriana Rodrigues, aunque una infografía de manera generalizada debe cubrir un contexto educativo alrededor de ella: se muestran elementos de aprendizaje con base en la vida cotidiana. Claro está que independientemente de que las infografías se diseñan acorde al tema o rubro a difundir, su punto focal es el aprendizaje.

También cabe destacar quee es una variante de una infografía, tiene las bases del binomio bI+T, tipografía, color, pero no sólo es un gran formato, es un producto de diseño con características que se distingue de la infografía.

Hay ciertas cualidades que la distinguen. La figura 1 es un prototipo que se realizó para el Centro Cultural Universitario Tlatelolco de 5.00x3.00 m. Pueden analizarse los elementos que con anterioridad se han mencionado. Se observa el titular que es la imagen corporativa de la institución, el cuerpo de texto donde se explica la información teórica acerca del inmueble arquitectónico, cubriendo las 5 W's y $1 \mathrm{H}$ :

1. ¿Qué? El Centro Cultural Universitario Tlatelolco, CDMX.

2. ¿Quién? Fue diseñado por Pedro Ramírez Vázquez, arquitecto mexicano reconocido internacionalmente por otras obras arquitectónicas, como el Estadio Azteca y el Museo de Antropología, en la CDMX.

3. ¿Cuándo? En 1966 se terminó de construir.

4. ¿Dónde? En Tlatelolco, CDMX, y da como resultado la plaza de las tres culturas por el entorno donde se encuentra: cultura prehispánica, cultura colonial y cultura moderna.

5. ¿Por qué? Se construyó para figurar en ese sitio la sede de Relaciones Exteriores en la CDMX, posteriormente forma parte de la Universidad Nacional Autónoma de México para la divulgación del arte, cuenta con cuatro museos.

6. ¿Cómo? Hoy en día es una construcción emblemática por las luces que conforman su exterior, instalación del artista Thomas Glassford. En la entrada tiene un escudo nacional y se da una breve explicación de la edificación, sus pisos, metros y pilotes que lo conforman. 
Tiene 5 infogramas: Relaciones exteriores, museos, dirección, horarios, planos, instalación, características, además de datos curiosos expresados en su formato. Es una hiperinfografía pedagógica, con foco gráfico que es el inmueble con la instalación, una composición de gráfico radial en el escudo nacional, y gráfico separado en museos y dirección; gráfico integrado en características. Soporte en lona de 12 onzas impresión directa (plotteo).

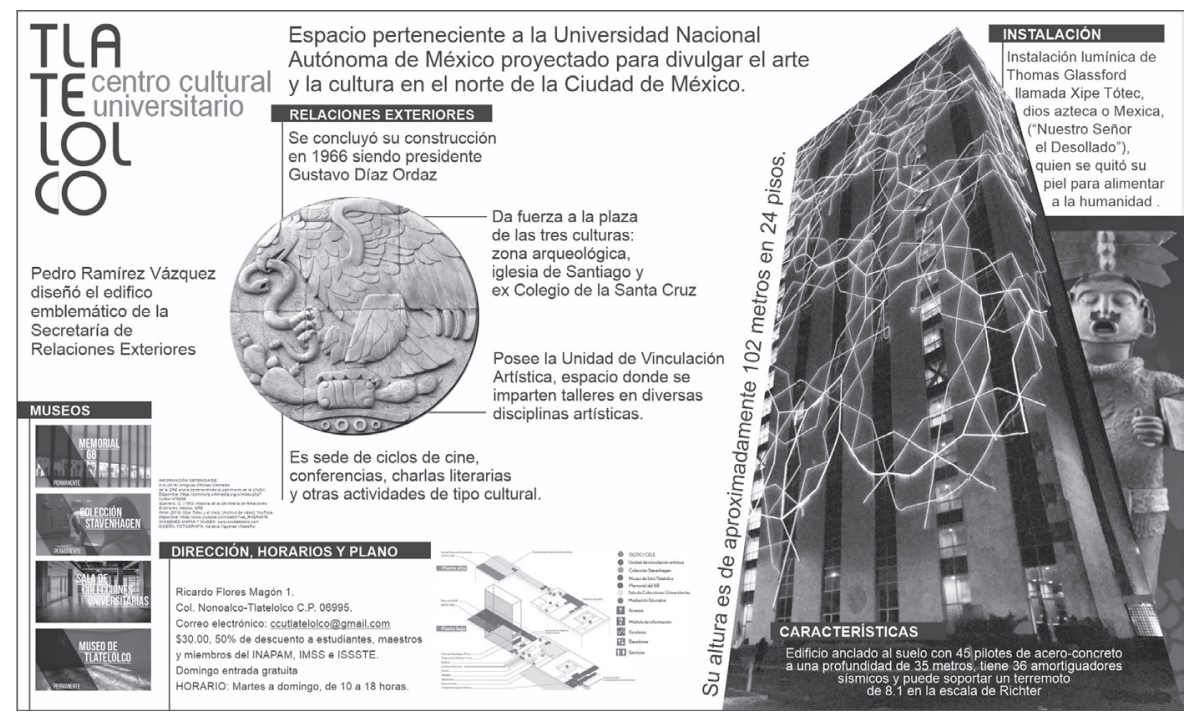

Figura 1. Prototipo de una hiperinfografía para el CCUTLATELOLCO, CDMX. Fuente: http://132.248.9.195/ptd2018/mayo/0774394/Index.html

Habiendo mostrado el ejemplo de una hiperinfografía, más aún, indicando los elementos que la determinan; amerita seguir reflexionando acerca de: ¿qué es una hiperinfografía?. Aquí está el meollo del diálogo, contiene información y grafía (bI+T) estructurada como infografía, pero con ciertos elementos conceptuales compositivos diferentes para su uso en gran formato, y que se mencionan a continuación:

a) Una hiperinfografía cubre con las respuestas de las preguntas de las $5 \mathrm{~W}$ 's y $1 \mathrm{H}$.

b) Existe o se muestra sinergia en el tiempo-espacio.

c) Contiene un conjunto de infogramas para su composición con el binomio Imagen+Texto, con un numeral mayor a los 3 .

d) Presenta una retícula compositiva para justificar los elementos ya que el espacio debe estar perfectamente acomodado a la situación de monumentalidad. 
e) El titular cuenta con una composición tipográfica, ya que esto hace que pueda diferenciarse del cuerpo o de subtitulares y aún de la propia infografía. Ello sucede debido a que al tener un mayor espacio, puede darse el lujo de hacer composiciones tipográficas. Deberá tener un titular san serif por el cuestionamiento de los patines que hace que se alargue el texto, es importante cuidar el interletrado en las grandes dimensiones y verificar que se distingan cada una de las letras. La extensión de los textos oscila entre los 45 y 75 caracteres de acuerdo con Bringhurst (2004, p.26). En un diseño editorial, en el caso de estos productos de diseño, se recomienda entre 20 y 50 caracteres de un tamaño entre los 4 y 6 $\mathrm{cm}$ de altura para su legibilidad (Vigueras, 2018).

f) El texto debe ser sencillo, simple, coherente y conciso por ser de un tamaño grande.

g) Cuidar el interletrado e interlineado para distinguir los caracteres.

h) Uso de bullets para su lectura y separación de textos.

i) Al hablar de la ortotipografía es necesario rigurosa corrección.

j) Las metáforas son utilizadas para sintetizar la información visual, las leyes gestálticas forman parte de lo compositivo tomando en cuenta las leyes de totalidad, concentración, continuidad, pregnancia, simplicidad, entre otras leyes de este tipo en uso.

k) El color puede usarse para agrupar temas, seleccionarlos o diferenciarlos, aunque se comprobó que el fondo blanco es mejor que el de color, precisamente por lo hiper y no entorpecer la lectura visual de la imagen-texto.

1) Usar un mismo estilo gráfico en la composición para agrupar y estandarizar.

m) El foco gráfico es primordial ya que le da orden, dinamismo y estructura a la composición.

n) La altura de colocación de piso a base de la hiperinfografía es de 80 a $100 \mathrm{~cm}$, tomando en cuenta la tabla de Julius Panero (1984).

ñ) Puede haber secuencias gráficas enmarcadas por un numeral, se recomiendan pocos pasos por la cuestión del tamaño y larga lectura al visualizarse éstos (Vigueras, 2018).

Se usarán ilustraciones, fotografías (siempre y cuando estén perfiladas), esquemas, líneas de tiempo, datos cuantitativos, y deben colocarse las referencias bibliográficas, hemerográficas consultadas, nombre de infografista(s), ilustrador(es), fotógrafo(s) o patrocinio(s). Pero, sobre todo, se deben cuidar los valores del código de ética del Colegio de Diseñadores Industriales y Gráficos de México, A.C. (CODIGRAM) con respecto al diseño, comunidad, usuario, tanto hacia el cliente, como hacia los colegas.

Estos puntos consignados se concluyeron y son el resultado del debate sobre los elementos hiperinfográficos, desarrollado a partir de los trabajos de y junto con los alumnos de la Universidad Tecnológica de México (una institución universitaria de la CDMX), de la carrera de Diseño Gráfico del $8^{\circ}$ cuatrimestre de la materia de Sistemas de Diseño III. Seguramente, con el paso del tiempo, irán agregándose lineamientos u otros puntos que en la probabilidad de hoy no son percibidos, pero que, con el paso de los años podrán ir sumándose a esta tarea. En la figura 2, se muestra un ejemplo de los alumnos de dicha institución, tratando de cubrir los puntos mencionados con anterioridad. 

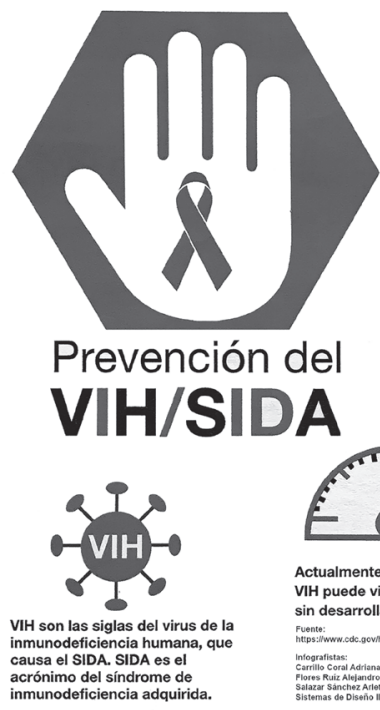

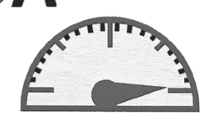

Actualmente, una persona con $\mathrm{VIH}$ puede vivir hasta 20 años sin desarrollar el SIDA.

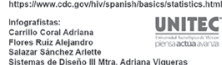

\section{Cifras}

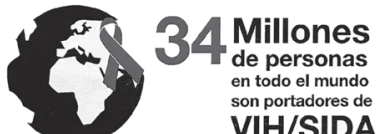

VIH/SIDA
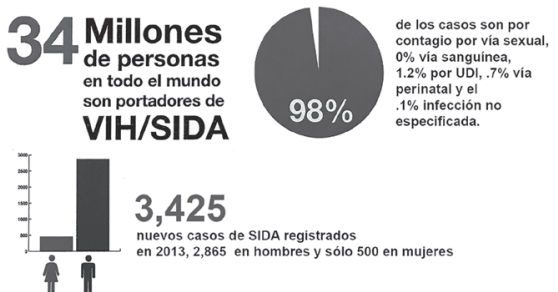

3,425

nuevos casos de sipa registrados

en 2013, 2,865 en hombres y sólo 500 en mujeres

\section{Síndrome de}

Inmunodeficiencia
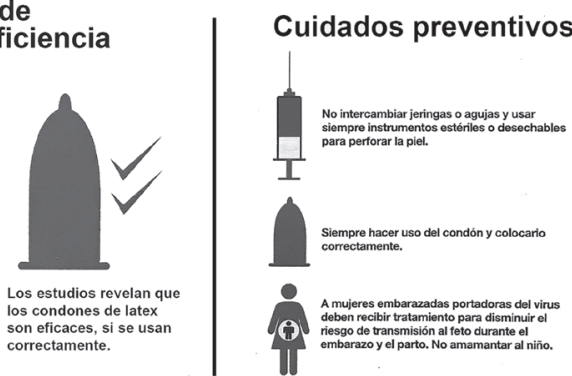

Figura 2. Diseño de hiperinfografía de alumnos de la Universidad Tecnológica de México. Diseño: Carrillo Coral Adriana, Flores Ruíz Alejandro y Salazar Sánchez Arlette. Fuente: http://132.248.9.195/ ptd2018/mayo/0774394/Index.html

Asimismo, el término, "hiperinfografía", se asignó en la currícula de la carrera de Diseño Gráfico de la mencionada institución (en las materias de Infografía I y II desde el 2015), donde se diseñaron dichas materias, para lo cual se integró el vocablo, y entró en vigor dicho temario en 2016 y, que tiene vigencia hasta finales de este año 2021, avalada por la Secretaría de Educación Pública (organismo nacional encargado de la educación en México). Se muestra en la figura 3, dando cuenta que ha ayudado a difundir el término hiperinfografía, aludiendo al diseño de dimensiones descomunales entre el alumnado de la licenciatura. 

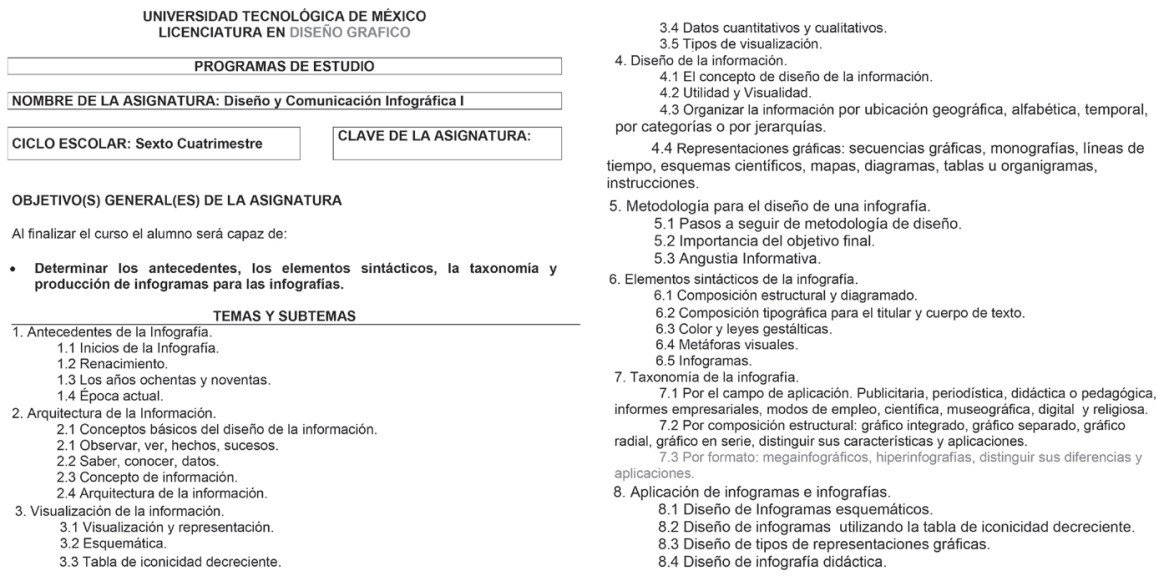

Figura 3. Temario diseñado por Adriana Vigueras 2013, hoy propiedad de la Universidad Tecnológica de México. Fuente: http://132.248.9.195/ptd2018/mayo/0774394/Index.html

\section{Conclusiones}

De acuerdo a lo expuesto, una hiperinfografía es de un formato monumental, que cubre necesidades de información y grafía, así como también requiere una mayor cantidad de tiempo para su realización como los megainfográficos de Ernesto Pérez o los megagráficos de Raymond Colle. Debe contener elementos compositivos adecuados, como texto, color, fotografías, ilustraciones, líneas de tiempo, datos estadísticos, bullets de separación, jerarquía, unidad, orden de lectura, metáforas, colocación y ubicación, entre otros. Cumplimentado lo antedicho, se concuerda con los parámetros de Cordeiro acerca de una infografía de cuarto nivel, en la que se utiliza la hiper media. Resta saber aún si a prefijo hiper seguirá refiriendo a la hiper media o se convertirá en una definición, y si sucederá lo mismo con el vocablo info de informática o de información, dando lugar a un contenido más exacto, un referencial;

Se logra, a partir de lo expuesto, denominar "hiperinfografía" a estos productos de diseño y comunicación de una forma taxativa, sin descartar que es este concepto va a seguir siendo trabajado. Se aspira a logar, en algún momento, una interpretación concreta y pertinente, que posiblemente no sólo sea referida al tamaño y a los infogramas y su mensaje inclusivo, sino algo más allá que los comunicadores y diseñadores puedan significar en dicha terminología. 
Nos adentramos cada día más en una sociedad, la sociedad de la información, en la cual lo visual prevalecerá sobre lo exclusivamente literario, por multitud de factores, como el de la simple sencillez de captación del mensaje.

De Pablos Coello [Mencionado en (Ferreres G., 1995, p. 3)]

\section{Bibliografía}

Alcántara E., Director Creativo. (28 de noviembre de 2014) Entrevista realizada en las instalaciones del periódico Excelsior. En persona. México.

Bringhurst, R. (2004) The elements of typographic style. $3^{\text {a }}$ ed. Estados Unidos de América: Hartley and Marks.

Colle, R. (2004) Infografía: tipología. Revista Latina de Comunicación Social. Canarias. España. julio-diciembre 8(7), 58. Disponible: https://www.redalyc.org/articulo. oa?id=81975801 y/o https://docplayer.es/60668897-Infografia-tipologias-por-raymondcolle.html

Colegio de Diseñadores Industriales y Gráficos de México, A.C. Disponible: http://www. codigram.org/codigo.pdf.

Cordeiro, W. Valero, J.L. (2018) Hiperinfografía: ¿onde está a visualização sintética no jornalismo de nova era? Revista Passagens. Programa de Pós-Graduação em Comunicação da Universidade Federal do Ceará. 1(9). Disponible: http://www.repositorio.ufc. br/bitstream/riufc/38540/1/2018_art_wrcordeirojlvsancho.pdf.

Cordeiro, W. (2019) Hiperinfografía. Uma proposta para o infográfico de quarta geração (Tesis doctoral). Brasil: Universidade Federal de Santa Catarina, Centro de Comunicação e Expressão, Programa de Pós Graduação em Jornalismo, Florianópolis. Disponible: https://repositorio.ufsc.br/handle/123456789/214529

Costa, J. (1998) La esquemática. España: Paidós.

De Pablos, José Manuel de. (1998) Infografía: tipologías. Revista Latina de Comunicación Social. Canarias. España. (5). Disponible: http://www.ull.es/publicaciones/ latina/biblio/ libroinfo/88depablos.htm.

De Pablos, José Manuel de. (2004) Siempre ha habido infografía. Revista Latina de Comunicación Social. Canarias. España. Enero-junio (57). Disponible: http://www.ull.es/ publicaciones/latina/colle2004/20040557colle.htm.

Ferreres, G. (1995) La infografía periodística. Madrid. Disponible: Tinta china.com

Fuentes, R. (2005) La práctica del diseñador gráfico. España: Paidós.

Holmes, N. (16 abr 2015) Using humor to inform. [Archivo de video]. YouTube. Disponible: https://www.youtube.com/watch?v=WB7DCEayj3w.

Leturia, E. (1998) ¿Qué es infografía? Revista Latina de Comunicación Social. Canarias. España. (4). Disponible: http://www.ull.es/publicaciones/latina/z8/r4el.htm.

Martínez, M. (2008) La infografía. Monografías. Disponible: https://www.monografias. com/trabajos59/la-infografia/la-infografia2.shtml\#xbiblio 
Panero, J. (1984) Las dimensiones humanas en los espacios interiores. $7^{a}$ ed. México: GG Pérez, E. (1999) Radiografía de una megainfografía. Revista Latina de Comunicación Social. Canarias. España. (20). Disponible: http://www.revistalatinacs.org/a1999eag/62coper/ coper2.htm

Rodrigues, A. (2 a 6 se septiembre de 2010) Visualização de dados na construção infográfica: abordagem sobre um objeto em mutação [Discurso principal]. Faculdade Social da Bahia, Salvador, BA. Intercom - Sociedade Brasileira de Estudos Interdisciplinares da Comunicação XXXIII Congresso Brasileiro de Ciências da Comunicação - Caxias do Sul, RS, Brasil. Disponible: http://www.intercom.org.br/papers/nacionais/2010/resumos/ R5-1783-1.pdf.

S/A (2011) Pequeño Diccionario de diseño. Reimers Design con licencia Creative Commons, Disponible: http://www.mediafire.com/file/rwcecj1eotdrxtn/Peque\%25C3\%25B1o_Diccionario_del_Dise\%25C3\%25B1ador.pdf/file

Sullivan, P. (1992) Graphic Information. Alemania: INCA-FIEJ Research Association.

Tricio, P. (2015) Abstracción en la pintura occidental sus elementos y su efecto en el espectador. (Tesis, Grado de Bellas Artes). España: Facultat de Belles Arts de Sant Carles. Universitat Politécnica de Valéncia. España. Disponible: https://studylib.es/doc/7598745/ abstracci\%C3\%B3n-en-la-pintura-occidental

Valero Sancho, José Luis. Doctor en Comunicación Audiovisual. Entrevista realizada vía correo electrónico, (joseluisvalero@uab.cat). Fecha: 29-30 de noviembre de 2014

Valero, J.L. (2000) La infografía de prensa. Ámbitos. No. 3-4 (2º semestre 1999-1er semestre 2000). Disponible: https://idus.us.es/bitstream/handle/11441/67171/revista-comunicacion-ambitos-03-04-117-125.pdf?sequence $=1$

Valero, J.L. (2001) La infografía: técnicas, análisis y usos periodísticos. Cataluña, España: Universitat Autónoma de Barcelona: Servei de Publicacions.

Vilches, L. (1987) Teoría de la imagen periodística. $3^{a}$ ed. Barcelona, España: Paidós.

Vigueras, A. (2018) Lineamientos para el diseño de hiperinfografías en el ámbito de la museografía universitaria (Tesis doctoral). México, Ciudad de México: Universidad Nacional Autónoma de México. CDMX. Disponible: http://132.248.9.195/ptd2018/ mayo/0774394/Index.html

Zunzunegui, Santos. (1995) Pensar la Imagen. $3^{\text {a }}$ ed. Madrid: Cátedra

\begin{abstract}
Design is a discipline that relies on images and texts with composition, color and formal elements, which make up the design itself; from editorials to the use of technological means, from two-dimensional to three-dimensional design objects (the design product aimed at audiences with different ages, genders, social classes and educational scope). Through this area, society is shown the cultural elements that have remained in history, objects, ideas, and even people are taught, disseminated or promoted. Any individual, throughout their existence, has designed at some point in their life; tried to have something visualized in a pleasant, contrasting, brilliant way or any other quality that
\end{abstract}


belongs to this discipline. There are different design products aimed at the user: brochures, posters or infographics; made up of image and text.

In this communication there will be a dialogue about the meaning of infographics and that of large formats, called "hyperinfographics". The latter is a design product that exceeds size standards, and in journalistic infographics, is preceded as mega infographics. That is, infographic printed formats in sheets size newspapers, approximately 16 sheets. In the case of hyperinfography, it was named as such because it is larger than a mega and exceeds the aforementioned dimensions.

Keywords: Dialog - infographic - hyperinfographic - dimensions - size - readability

Resumo: O design é uma disciplina que conta com imagens e textos com composição, cor e elementos formais, que constituem o próprio design; dos editoriais ao uso de meios tecnológicos, dos objetos de design bidimensionais aos tridimensionais (produto de design voltado para públicos de diferentes idades, gêneros, classes sociais e âmbito educacional). Por meio dessa área, são apresentados à sociedade os elementos culturais que ficaram na história, objetos, ideias e até pessoas são ensinadas, disseminadas ou promovidas. Qualquer indivíduo, ao longo de sua existência, projetou em algum momento de sua vida; tentei que algo possa ser visualizado de forma agradável, contrastante, brilhante ou qualquer outra qualidade que pertença a esta disciplina. Existem diversos produtos de design dirigidos ao utilizador: brochuras, posters ou infográficos; composto por imagem e texto. Nesta comunicação haverá um diálogo sobre o significado dos infográficos e dos grandes formatos, os chamados "hiperinfográficos". Este último é um produto de design que ultrapassa os padrões de tamanho e na infografia jornalística é precedido como mega infografia. Ou seja, infográfico em formatos impressos em folhas de jornais, aproximadamente 16 folhas. No caso da hiperinfografia, recebeu esse nome por ser maior que um mega e ultrapassar as dimensões citadas.

Palavras chave: Diálogo - infográfico - hiperinfográfico - dimensões - tamanho - legibilidade

[Las traducciones de los abstracts fueron supervisadas por el autor de cada artículo] 